\title{
Solar Heater Technologies Selection Using Multi-criteria
}

\section{Analysis}

\author{
Mohsine Bouya ${ }^{1}$, Badr Abou El Majd ${ }^{2}$, Merieme Agdid ${ }^{1}$ and Abdellatif Ben Abdellah ${ }^{1,3}$ \\ 1. Renewable Energy and Advanced Materials Laboratory, International University of Rabat, Parc Technopolis, Sala Al Jadida \\ 11100, Morocco \\ 2. Computer Science and Decision Aiding Lab, Hassan II University, Casablanca 20100, Morocco \\ 3. Innovation and Management of Industrial Systmes Laboratory, College of Science and Techniques of Tanger, University \\ Abdelmalek Essaidi, Tanger 90 100, Morocco
}

Received: November 17, 2014 / Accepted: January 04, 2015 / Published: April 30, 2015.

\begin{abstract}
Regarding sun's potential in Middle East and North Africa zone and particularly in Morocco, we focus our work on the development of the knowledge and information concerning the solar heaters for domestic applications, in order to help the industrial and the consumer to select an adaptive technology. As a result, a Moroccan mapping of solar water heating systems is presented in this work. This mapping concerns two technologies commonly used: the FPC (flat plate collectors) and the ETC (evacuated tubes ones). It is based on three criteria: firstly, the efficiency of the STC (solar thermal collectors); secondly, the economic aspect and at last, the reliability requirements. Based on these information, the multi-criteria outranking methodology PROMETHEE (preference ranking organization method for the enrichment evaluations) allows us to define an adequate solar heater technology linked with the climatic zoning of Morocco.
\end{abstract}

Key words: Mapping, solar water heating, flat plate collector, evacuated tubes collectors, PROMETHEE.

\section{Introduction}

The SWHSs (solar water heating systems) are highly affected by the climatic environment where they are used. Therefore, there must be an optimal choice for each region of Morocco. The STC (solar thermal collector) is the most important part of the SWHS. Consequently, the performances of these systems depend basically of those of the STC used because the thermal exchange between the sun and the heating fluid occurs at this level. Moreover, it is the most expensive part of the system.

In this mapping investigation, we concentrated the work on the technologies of STC. We studied three different aspects related to the technical performances, the economic aspect and the reliability requirements of

Corresponding author: Mohsine Bouya, associate professor, research fields: valorization and transfer. Email: Mohsine.bouya@uir.ac.ma. selected technologies of STC. We are concerned by two technologies of STC in this work, which are the most used to heat the domestic water: the flat plate and evacuated tubes collectors.

\section{Experimental Comparison of the Collectors}

Before starting the study, an experimental comparison of the technologies of collectors is programed. It aims to compare the performances of FPC (flat plate collectors) and ETC (evacuated tubes collectors).

The manipulations setup has been established from the European standard "EN 12975-2". We have selected the test of thermal performances. Thanks to this test, we will be able to compare the real efficiency of fore-mentioned technologies. On behalf of using the real data to compare the studied technologies, the solar 
irradiance prediction models by area are used to establish a very accurate sizing of STC systems for an optimized deployment.

\section{Definition of the Climatic Zoning}

The climatic zoning has been based on the solar irradiations mapping of Morocco. As shown by Fig. 1 [1], this mapping divides Morocco to five homogenous zones.

We combined the mapping represented above, in Fig. 1, with another one [2] fulfilled by MNADREEE (Moroccan National Agency for the Development of Renewable Energy and Energy Efficiency) in collaboration with MNWD (Moroccan National Weather Directorate). The second mapping is represented in Fig. 2 [2].

We opted for the climatic zoning of the ADEREE (Agency for the Development of Renewable Energy and Energy Efficiency) because it gives more details about each zone in terms of profile of temperature. Furthermore, the zonings of the two mappings coincide in most regions.

\section{Technical Aspect}

To evaluate the technical aspect, we calculated the surface needed of FPC and ETC to respond to the same daily requirement of hot water and solar fraction.

We started from the basic definition of the efficiency of the system. It may be calculated by Eq. (1) [3]:

$$
\eta=\frac{\text { Energy transmitted to Heat fluid }}{\text { Energy received from the sun }}
$$

The energy transmitted to the heating fluid and the one received from the sun may be replaced by their expressions to deduct Eq. (2) [4]:

$$
\eta=\frac{\mathrm{DRHW} \cdot \mathrm{SF}}{\mathrm{Ir} \cdot A}
$$

where, DRHW (daily requirement of hot water) is daily requirement of hot water, $\mathrm{SF}$ is the solar fraction, $I r$ is the solar irradiations, and $A$ is the area of the STC. The parameter DRHW can be calculated using Eq. (3) [5]:

$$
\text { DRHW }=1.6 \times 10^{-3} \times V \times\left(T_{r}-T_{C W}\right)
$$

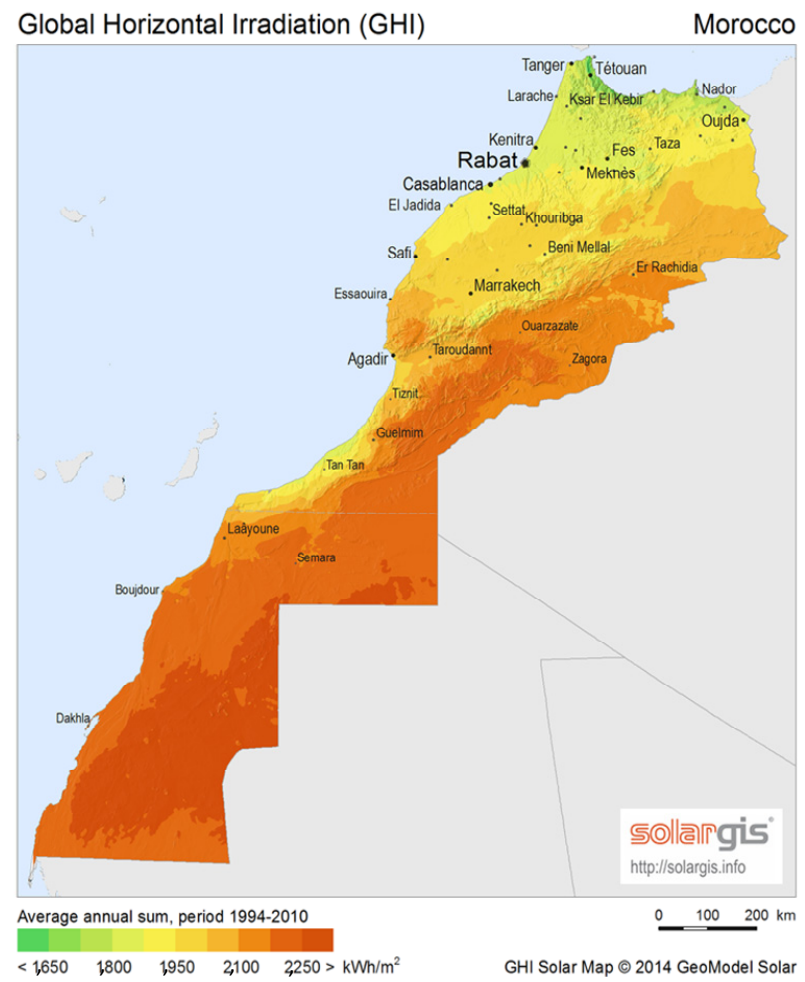

Fig. 1 Solar irradiations mapping of Morocco.

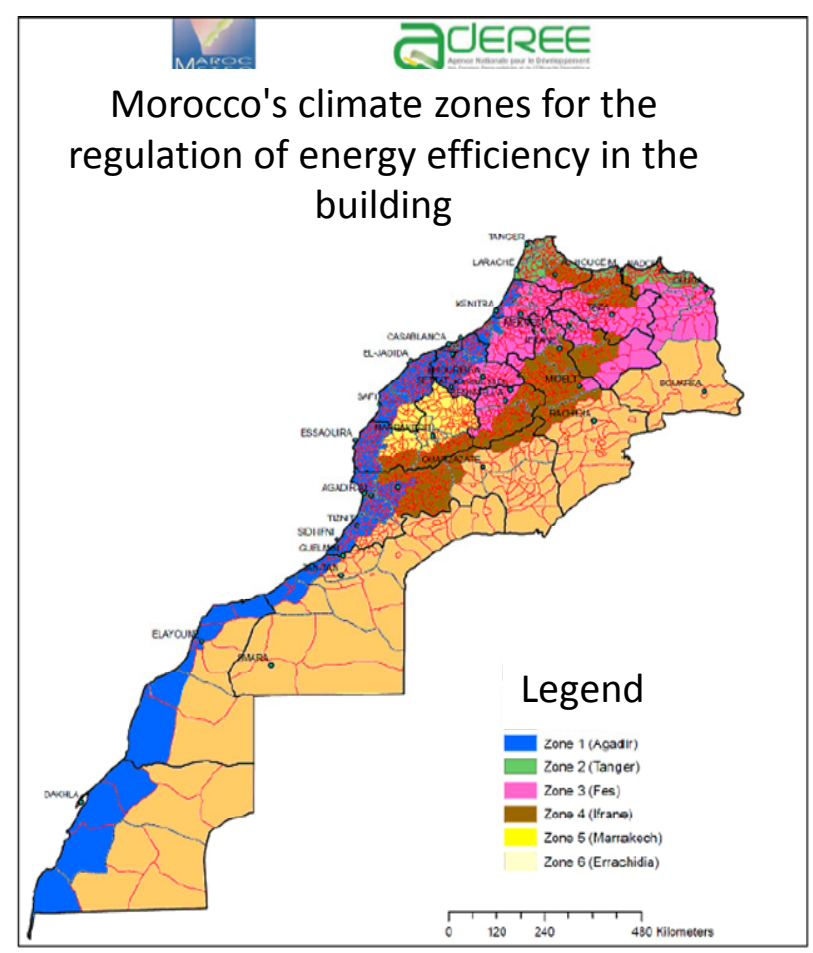

Fig. 2 Climatic zoning-ADEREE.

where, $V$ is the volume needed per day, $\operatorname{Tr}$ is the required temperature of hot water $\left({ }^{\circ} \mathrm{C}\right)$, and $T_{C W}$ is the temperature of cold water $\left({ }^{\circ} \mathrm{C}\right)$. 
In this study, the DRHW has been taken equivalent to the daily need of 250 persons. In the sizing of STC, the temperature of each zone and their solar irradiations has been taken from the software Meteonorm. The assumptions made in this sizing can be summarized in Table 1.

We worked with efficiencies collected from Ref. [6]. After the experimental that comparison will take place, we will inject the efficiencies measured experimentally.

Thanks to Eq. (3), we could calculate the area needed of the technologies studied all over Morocco to respond to the specificities detailed in Table 1. The results may be summarized in Table 2 .

The sizing table (Table 2) shows that, the difference of surface needed between the FPC and ETC varies from $16 \mathrm{~m}^{2}$ to $20 \mathrm{~m}^{2}$. And consequently, we need lesser areas for ETC deployment. Regarding this result, we can conclude that we need a lesser surface for ETC deployment then the FPC one. And to conclude about the adapted STC technologies for all Moroccan zoning, we should introduce the economic and reliability studies.

\section{Economic Aspect}

After the worldwide supplier's identifications for each type of studied STC, we have contacted several Moroccan companies for quotation demands. Table 3 gives the average of the prices of the FPC and ETC in Morocco (small existing surface in the market: $2 \mathrm{~m}^{2}$ ). The prices are given in Table 1, include all the taxes.

The investment cost in terms of STC has been calculated for the sizing done in the last part all over the

Table 1 Assumptions of the sizing in each zone.

\begin{tabular}{ll}
\hline Temperature of cold water & $\begin{array}{l}\text { Average of the annual } \\
\text { temperature }\end{array}$ \\
\hline Temperature of hot required & $60{ }^{\circ} \mathrm{C}$ \\
Required volume & $7,500 \mathrm{~L}$ \\
$\mathrm{SF}$ & $70 \%$ \\
Efficiency of FPC & $50 \%$ \\
Efficiency of ETC & $65 \%$ \\
Solar irradiations Ir & Average of the annual solar \\
\hline
\end{tabular}

Table 2 Results of the sizing.

\begin{tabular}{lll}
\hline Zone & $\begin{array}{l}\text { Area of FPC } \\
\left(\mathrm{m}^{2}\right)\end{array}$ & $\begin{array}{l}\text { Area of ETC } \\
\left(\mathrm{m}^{2}\right)\end{array}$ \\
\hline Zone 1 (Agadir) & 78 & 60 \\
Zone 2 (Tangier) & 80 & 62 \\
Zone 3 (Fes) & 82 & 64 \\
Zone 4 (Ifran) & 82 & 62 \\
Zone 5 (Marrakech) & 73 & 56 \\
\hline Zone 6 (Er-Rachidia) & 76 & 60 \\
\hline
\end{tabular}

Table 3 Average prices (in Moroccan Dirham (MDH)) of FPC and ETC.

\begin{tabular}{ll}
\hline STC & Price \\
\hline FPC & 3,500 \\
ETC & 5,000 \\
\hline
\end{tabular}

Table 4 Investment cost in terms of STC in the different regions of the climatic zoning.

\begin{tabular}{lll}
\hline Zone & \multicolumn{2}{l}{ Price of the area of Price of the area } \\
& FPC (MDH)) & of ETC (MDH)) \\
\hline Zone 1 (Agadir) & 136,500 & 150,000 \\
Zone 2 (Tangier) & 140,000 & 140,000 \\
Zone 3 (Fes) & 143,500 & 160,000 \\
Zone 4 (Ifran) & 143,500 & 155,000 \\
Zone 5 (Marrakech) & 126,000 & 155,000 \\
Zone 6 (Er-Rachidia) & 133,000 & 150,000 \\
\hline
\end{tabular}

zones of Morocco. Table 4 synthesizes the investment cost all over the zones in terms of Solar heating collectors.

Table 4 shows that, the use of FPC in different predefined areas is significantly cheaper because of their low price. Furthermore, the percentage of the difference in investment cost varies from $8 \%$ to $13 \%$.

\section{Aspect of the Reliability}

Common failures that may influence the performances of the STC are listed in Table 5. The two technologies studied are sensitive to these failures but with a different degree of severity. The signs + , - and $=$, respectively mean more sensitive, less sensitive and equal sensitivity.

The mentioned failures in Table 5 are the direct result of one or more given climatic factors. Table 6 connect each failures to the associated climatic factors.

The problem of scaling will not be taken into consideration in this study, since it can be avoided if 
we do not opt for an open circulation.

After studying the parameters that causes each failure data, we summarize in Table 7 the predominant failure in each area.

Table 7 shows that, FPC are not recommended in areas 4 (Ifrane), 2 (Tangier) and 1 (Agadir) because of the problems of corrosion and gel. We recommend, therefore, the ETC in these regions. In the other areas, 6 (Errachidia), 3 (Fez) and 5 (Marrakech), the overheating problem requires the use of FPC technologies.

According to all criteria (technical, economic and reliability), the final mapping is summarized in Fig. 3.

\section{Multi-criteria Analysis}

Various issues need to be considered when comparing the technologies of collectors (FPC and ETC), in particular, economic efficiency, climatic impacts, etc. The potential of each technology to achieve these goals can be evaluated using different criteria. So, the MCDM (multi-criteria decision making) methods seem to be an appropriate choice for comparing FPC and

Table 5 Failures caused by climatic factors.

\begin{tabular}{lll}
\hline Failures & FPC & ETC \\
\hline Overheat & - & + \\
Corrosion & + & - \\
Scaling & + & - \\
Freezing problem & + & - \\
\hline
\end{tabular}

Table 6 Environmental factors related to each failure.

\begin{tabular}{ll}
\hline Failures & Climatic factor associated \\
\hline Overheat & Average summer temperature \\
Corrosion & Humidity \\
Scaling & Rate of limestone in water \\
Freezing problem & Snow \& average winter temperature \\
\hline
\end{tabular}

Table 7 Investment cost in terms of STC in the different regions of the climatic zoning.

\begin{tabular}{ll}
\hline Zone & Predominant failure \\
\hline Zone 1 (Agadir) & Corrosion \\
Zone 2 (Tangier) & Corrosion \\
Zone 3 (Fes) & Overheat \\
Zone 4 (Ifran) & Freezing problem \\
Zone 5 (Marrakech) & Overheat \\
Zone 6 (Er-Rachidia) & Overheat \\
\hline
\end{tabular}

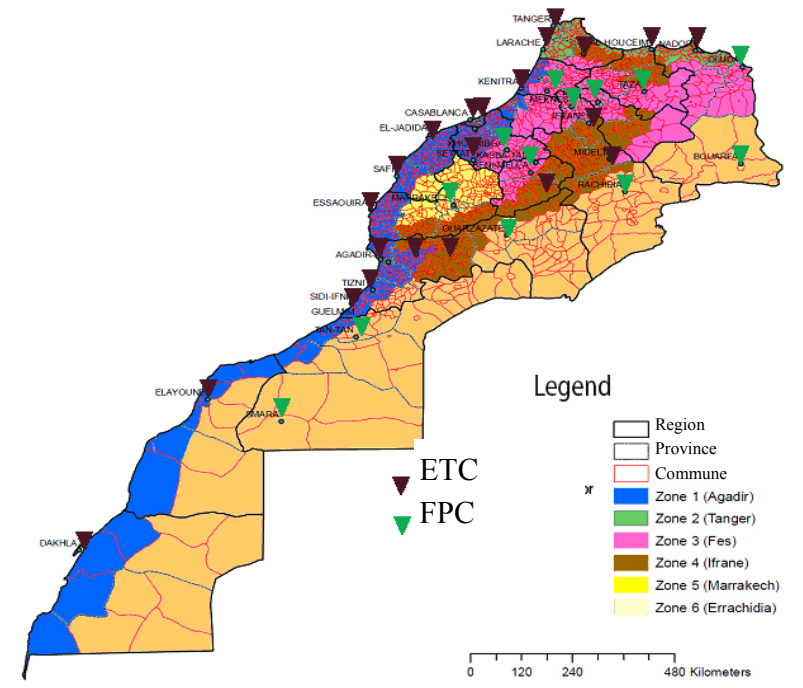

Fig. 3 Final mapping of solar water heatings technologies in Morocco.

ETC technologies. These methods can handle both quantitative as well as qualitative criteria and analyze conflict in criteria and decision makers [7]. We use in particular the class of MADM (multi-attribute decision-making) methods, the most popular MCDM methods, to solve our problem. This class contains several methods: AHP (analytic hierarchy process), PROMETHEE, ELECTRE (elimination and choice expressing reality), MAUT (multi-attribute utility theory), etc. Following real life observations, the decision makers are often not fully aware of their preferences, or that they are not able to express these in unambiguous way. Thus, the PROMETHEE method is selected here as a methodological basis which provide an appropriate support to the decision makers.

The PROMETHEE methods were developed by Brans et al. [8, 9] to support a decision maker rank partially (PROMETHEE I) or completely (PROMETHEE II) a finite number of options by using the outranking principle. First, we identify different options and objectives of the decision problem. Then, we express the objectives in form of evaluation criteria associated to the performance functions and weights. The next step consists to complete the EM (evaluation matrix) by combining preference information (thresholds and weights) with performance data. Finally, we apply the PROMETHEE procedure. Note 
that, the preference structure of PROMETHEE is based on pairwise comparisons.

Let us apply the PROMETHEE II method to our multi-criteria problem. The subject is to compare two technologies (FPC and ETC) for each geographic zone (Zone 1 (Agadir), Zone 2 (Tangier), etc.), each zone corresponds to one scenario. Three criteria have been selected for the evaluation: the efficiency, the cost, the FCF (failures caused by climatic factors). The index is expressed in a scale of 1 (more sensitive), 2 (equal sensitivity) and 3 (less sensitive). The efficiency has to be maximized whereas the cost and the FCF have to be minimized.

For the first scenario, the data for the evaluation, the type of each criterion and the values of each corresponding parameters are shown in Table 8. To simplify, we suppose that, the decision-maker chooses the usual preference function (Type I) and the entire criterion correspond to the same weight. It means that the effect is similar for small and large criteria differences. This leads to the following results. Fig. 4 shows that, reliability is conflicting with cost and efficiency. According to the position of $\mathrm{Pi}$ vector, which shows the direction of the compromise results, we can conclude that the best alternative is the FCP

Table 8 Alternatives for the first scenario (Zone 1).

\begin{tabular}{llll}
\hline & Efficiency & Cost & FCP \\
\cline { 2 - 4 } & Type I & Type I & Type I \\
\hline FCP & 78 & 135,500 & 3 \\
ETC & 60 & 150,000 & 1 \\
\hline
\end{tabular}

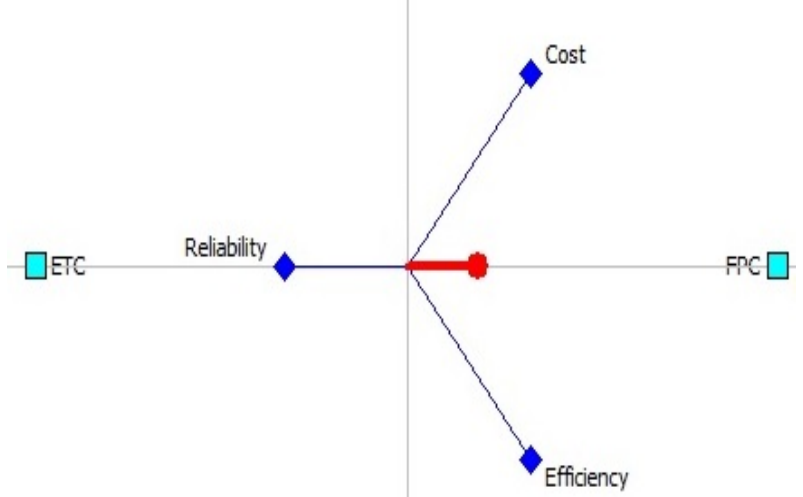

Fig. 4 First scenario, GAIAA (geometrical analysis for interactive aid) plane.
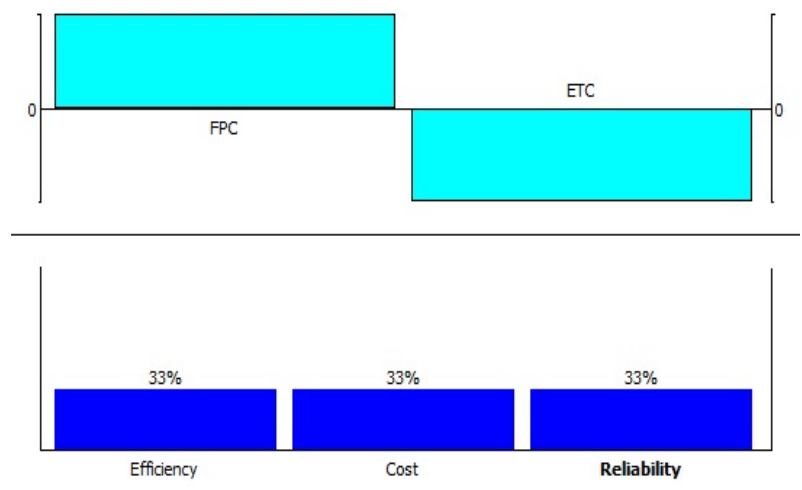

Fig. 5 First scenario, comparaison between FCP and ETC.
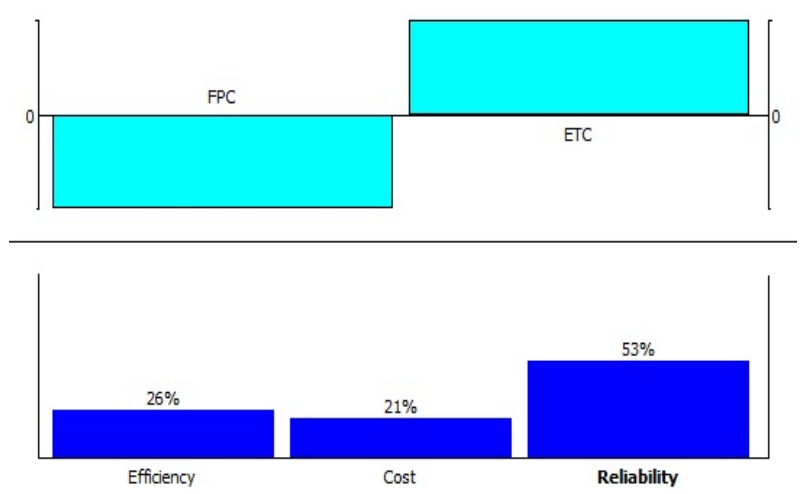

Fig. 6 First scenario, comparaison between FCP and ETC for different value of the weighted coefficients.

Table 9 Final decision for each zone.

\begin{tabular}{lllllll}
\hline & Zone 1 & Zone 2 & Zone 3 & Zone 4 & Zone 5 & Zone 6 \\
\hline FCP & $\mathrm{X}$ & $\mathrm{X}$ & $\mathrm{X}$ & $\mathrm{X}$ & $\mathrm{X}$ & $\mathrm{X}$ \\
ETC & & $\mathrm{X}$ & & & & \\
\hline
\end{tabular}

(flat plate collectors) technology. This is confirmed by Fig. 5 for equal weighted coefficients. The Fig. 6 illustrates the impact of the weighted coefficients on the final results.

By using the same methodology for the others scenario, Table 9 gives the best technology corresponding to each zone.

\section{Conclusions and Perspectives}

Thanks to the multi-criteria analysis based on the technical, economic and reliability studies, we have established a Moroccan mapping of domestic solar heaters technologies, which allows us to identify the most appropriate technology for each region of Morocco. 
This study will be very useful for:

- The solar heater industrials, to propose an adapted solution by Moroccan zoning, for an optimal utilization with a good sizing;

- The consumer will be very informed of an adapted heat solar technology and capable to choose a low cost solution with a higher performance.

On the perspective, we are planning to work on software based on a multi-criteria analysis that will help the end-user to choose the adapted technologies.

\section{Acknowledgments}

We take this opportunity to express our profound gratitude and deep regards to Hamidi, Y. for his inspiring and priceless advices. We would like to express our special appreciation and thanks to Bouissa, Y. for his exemplary guidance, monitoring and constant encouragement. We also want to thank Elouahabi, M. for his availability and good directions.

\section{References}

[1] Moroccan Agency for Solar Energy. 2010. "Moroccan Solar Plan, Solar Irradiation Map.” Moroccan Agency for Solar Energy. Accessed November 12, 2013. http://www.masen.org.ma/?Id=15\&lang=fr.
[2] Moroccan Office of Meteorology. 2008. "Morocco's Climate Zones for the Regulation of Energy Efficiency in the Building: 1999-2008". Accessed November 12, 2008. http://www.aderee.ceeb.ma/pdf/zonages_climatiques.pd.

[3] Kalogirou, S. A. 2004. "Solar Thermal Collectors and Applications." Progress in Energy and Combustion Science 30 (3): 231-95.

[4] Hayek, M., Assaf, J., and Lteif, W. 2011. "Experimental Investigation of the Performance of Evacuated-Tube Solar Collectors under Eastern Mediterranean Climatic Conditions." Energy Procedia 6 (June): 618-26.

[5] Zambolin, E., and Del Col, D. 2010. "Experimental Analysis of Thermal Performance of Flat Plate and Evacuated Tube Solar Collectors in Stationary Standard and Daily Conditions." Solar Energy 84 (8): 1382-96.

[6] Föste, S., Giovannetti, F., Ehrmann, N., and Rockendorf, G. 2014. "Performance and Reliability of a High Efficiency Flat Plate Collector-Final Results on Prototypes." Science Direct, Energy Procedia 48 (February): 48-57.

[7] Climaco, J. 1997. Multicriteria Analysis. New York: Springer.

[8] Brans, J. P., Mareschal, B., and Vincke, P. 1984. PROMETHEE: A New Family of Outranking Methods in Multicriteria Analysis, Operational Research. Edited by Brans, J. P. North Holand: Elsevier Science Publisher.

[9] Brans, J. P., and Vincke, P. A. 1985. "Preference Ranking Organization Method (The PROMETHEE Method for MCDM)." Management Science 31 (6): 647-56. 